\title{
A Proposed Model of Legal Remedies to Manage Human Resource Issue: A Case Study of an Open University
}

\author{
Tahira Bibi \\ Lecturer \\ Department of EPPSL, AIOU \\ tahira.naushahi@aiou.edu.pk
}

\begin{abstract}
Universities are investing their precious resources to manage legal issues. When a conflict arises between the management and employees at the workplace they prefer to go to court and not rely on trust the internal mechanism to resolve the issues which leads to wastage of financial resources, misuse of the potential energy of the employee as well as employers and damage organizational work environment. The main purpose of the present study was to explore the existing model of legal issues regarding human resource management and propose a sustainable model to overcome the issues for efficient utilization of resources. The data were collected through primary and secondary sources. First, documents were carefully analyzed and legal files were reviewed. After it, semi-structured interviews were taken of the legal advisors, legal managers and human resource manager of the open distance learning University. Data were analyzed through NVivo software. Presently, universities have various committees and syndicate/executive council is the appellate body against the decisions of the committees. Most employees prefer to go to the courts as a legal remedy to find relief. Whereas the proposed model which has the following three components 1) Nature of the Issue 2) Procedure to Resolve the Issue and 3) Enforcement of the Decision of the Council. Courts will take only cases on the question(s) of law.
\end{abstract}

Keywords: Human Resource Management, Legal Remedies, Open University, Legal issues

\section{Introduction}

Human resource management regulations come from laws that are passed by the legislators, local governing bodies and executive orders. The purpose of these laws is managing employee's attitude and behavior so that the employee's contributions can be influenced for enhanced organizational performance. This project aims to explore and analyze the legal and regulatory issues which underpin the contemporary human resource management issues (Clardy, 2003). It includes consideration of such matters as recruitment and selection, contract employment issues, performance appraisal, equal opportunity and anti-discrimination, termination of employment, remuneration, rewards and employee benefits, employee health and safety, besides other HRM related issues. These issues form the base for many other problems for the public sector universities because nearly all the operations of the public sector universities are dependent upon the human resource strengths. The streamlined human resource management not only means that the employees will be able to perform better, but it also ensures that the overall performance of the organization can be enhanced and improved through the collective efforts in effective human resource management (Murphy, 2018). Human resource management is a critical part in managing the whole staff of university from lower level to the level of intellectuals in a way that not only their performance and achievement is aimed towards the individual growth, but also performs a 
key part in the achievement of goals and objectives of the university. Human resource management in a university is linked to the following direct factors in relation, a) hiring of employees, b) development of employees in relation to their capacity building, c) enhancement of capabilities of employees, d) utilization of skills and knowledge of the individuals, and e) maintenance and compensation of the services provided by the employees in relation with the job and performance as well as other organizational requirements. The core role of the human resource management is the provision of strength in relation to the job and performance and other requirements of the organization so that they are completely understood and adhered by the employees thus they can provide the best performance in understanding and undertaking the assigned role (Punia \& Saharam, 2012).

For the better understanding and exploration of the human resources cycle in a university environment especially in case of legislative policies and procedures, it is essential to examine and understand the legal records along with gathering the views and perceptions of people who went through the legal cycle or had dealt with the legal scenarios arising in a university.

The phrase "Human Resource" reflects the concept of individuals involved as a workforce, with multiple and distinctive skill sets who perform in their designated areas to achieve the collective goals and targets of the organization. Other terms like "manpower", "labor" or simply "people" are also used in the same context (Dubravska \& Solankova, 2015). Management of human resource activities means managing of those activities which are involved in acquiring, training, appraisals, and ultimately compensating the human resource in respect of the efforts provided by the individuals in performance of their assigned duties. At the organizational level especially in case of public sector organizations, the human resource management means the set of policies, legislations, and practices designed by the organization for the individuals to act upon or within, so that tasks can be performed in an organized manner to gradually reach individual as well as the organizational goals. In a public sector university, individuals from diversified backgrounds, having versatile skill sets, perceptions, beliefs and values are combined at a single workplace to perform the organizational tasks (Murphy, 2018). Management of people with such rich backgrounds is always a challenge for the top management or the legislative bodies of the organizations or public sector universities. These differences can become a cause of problem at the organizational level if they are not handled with due care and vigilance. The standard procedures and legislatives ensure that the operational activities in the organization become streamlined and that every individual must have a guided path for smooth performance of duties. Still such legislatives and procedures sometimes become vulnerable and insufficient to tackle the human resource issues due to limitations and gaps (Abdulai, 2000). The effective human resource management also ensures that the individuals develop the ability of decision making at the individual level so that the operations of the organization can have the smooth functionality to achieve the desired goals and targets of the organization (Abdulai, 2000).

Public universities cannot work in a standalone or isolated environment, where a single person has multiple responsibilities and a great number of people depend upon the performance and operations of the organization. Due to this fact, the departments within an organization and different operations are broken down into smaller clusters known as sections, or cells etc. (Rosenbloom, 2010). This categorization of the organization ensures that the operations are run smoothly and burden does not fall only on few individuals only within the organization. These sections can then be further allotted among different individuals with reduced duties and responsibilities to work more efficiently and effectively. The quality of human resource in any organization depends upon the quality of legislations and procedures adopted by the organization 
for the management of human resource (Iqbal, Arif \& Abbas, 2011). There are three aspects which significantly affect the performance of human resource in a public sector university namely; technological factors, demographics and diversity, in addition to globalization factors.

The importance and significance of HRM practices was ignored for a long period of time in public sector universities of Pakistan (Iqbal, Arif \& Abbas, 2011). This was mainly due to the fact that there was very little understanding about the current concepts and practices in relation to the HRM. The factor of diversified individuals with different values also played a major role as a hindrance and challenge in effective practicing of HRM practices in public sector universities. Also, the factor of rapid technological advancement played the role of a roller coaster in uprising of retaliation from the individuals who have less knowledge of technology hence causing high level of resistance in adoption to this change (Ashraf, 2017). Due to the prevailing quota system in Pakistan and low standards of check and balance in the recruitment processes, the issues in the HRM starts from the very beginning in public sector universities. Also, the importance of training and orientation of employees was realized very late. Even at present, many public universities have a very weak, outdated and insignificant book of HR procedures and legislatives which affects the organizational performance at large. Some universities still do not have separate human resource departments and the HR operations are dealt with at the respective departmental level or at the administrative level. The bureaucratic culture of the public sector universities is also playing a major part in reluctance towards the effective HRM practices (Ijaz Khan \& Shamsudin, 2016).

In a research conducted by Arif \& Hasan, (2013), the researcher identified that the factors such as lack of funding, lack of research culture in public universities, politics, and lack of qualified staff affects the effective HRM practices in domains of selection, training, appraisals, compensations, career planning, and employee participation, etc. These challenges and shortcomings are the main reasons that public universities of Pakistan are lagging behind in competing with the top universities of the world. The competitive advantages in the discipline of HRM for public sector universities cannot be ignored or put at the secondary position in priority list. The researcher also identified that no significant research has been done in the field of HRM practices adopted by the public universities of Pakistan to address the issues of human resource (Arif \& Hasan, 2013).

Another researcher Ahmed, (2010) identified that there is a friction between the top management, faculty and the administrative staff of the public sector universities in relation to the legislative body authority and power for HRM issues. This is evident from the views and opinions of administrative staff that they are never consulted during the development of the legislative body in the public university. In fact, the laws and procedures are considered as a burden on the shoulders of administrative staff of university. Also, the researcher witnessed that no efforts have been made to bridge this gap and friction, nevertheless this fact is ignored completely that bridging this gap would enhance and improve the organizational performance. The researcher also found that due to the weak accountability laws in public universities, the legislations for HRM practices are not taken seriously by the individuals or employees of the organization (Ahmed, 2010).

Human Resource management the Service providing organizations especially public sector universities has large number of human resources which is the core asset of each university. Management of this human resource requires some well-defined and properly implemented legislations or laws. Dispute among employees and Management is a natural phenomenon. Conflict of interest leads to dispute. Well defined law and procedures helps to manage the human resource and disputes. Legislations for the management of human resource in a public sector university face number of challenges and issues in domain of recruitment, employment contracts, 
performance appraisals, provision of equal opportunity and anti-discrimination, termination of employment term, remuneration or salary slabs, employee benefits, health and safety considerations for employees.

\subsection{Statement of the Problem}

Legal issues faced by the public sector university in HRM are normally addressed according to the by-laws and standardized protocols of legislation. But universities are struggling hard in properly managing and solving such issues. Complications in the HRM issues can affect the overall performance of the public sector universities because smooth delivery of assigned duties by individuals as well as the collaborations between different departments is essential for the achievement of overall goals of universities. Hence there is a need to identify the critical risk factors which are influencing the effective HRM and efforts are needed to be made to bridge the gap between legislations and actual legal practices for HRM issues in Public Sector University. So that the Public resources may be used in right and efficient way.

\subsection{Objectives}

The core objectives of the study were,

a) to identify legal issues affecting the human resource practices in higher educational institutions.

b) to explore the gaps between law and procedures of human resource management and their implementation.

c) to explore the factors affecting the legal system from relevant cases to involving human resources management issues.

\section{Research Methodology}

Development of research methodology is an essential process for the provision of careful considerations to research study and for the choice of an appropriate approach for its conduction (Pathirage et al., 2005).

\subsection{Research design}

The current study has adopted the philosophical assumption of ontological stance for examining the factors which are influencing the legal system in the management of human resource issues in Public Sector University. Ontological psychological assumption describes the views on the nature of reality that whether there is an objective reality which really exists or whether reality is subjective and is only created in our minds (Flowers, 2009). Ontology has two main views which are objectivism and subjectivism. In the current research, the subjectivism views or the relativism approach has been adopted to investigate and explore the factors which are affecting the legal issues of HRM in public university.

The current study used the epistemological position of interpretivism which involves conduction of research with people rather than objects and it concerns the differences among humans as social actors (Saunders et al., 2009). This research was an exploratory study in which inductive theoretical approach was adopted by the researcher to examine the phenomenon in a context of HRM and legal issues faced by the public university. 


\subsection{Participants of the study}

Qualitative research approach was employed to achieve the desired objectives of the study. Case study research design was used to administer the qualitative data collection research methods from the Allama Iqbal Open University, as a case study. Two interview protocols for the relevant to the subject of the study of employees (registrar department, legal section and HRM section) and legislative personnel of AIOU were considered as the population of the qualitative study from which the representative sample was selected through the purposive sampling technique. Semi structured interviews were used as a qualitative data collection tool to get the views and opinions of the legislative personnel from AIOU regarding the legal issues faced by the Public Sector University in managing the human resource. Professional lawyer dealing with cases in relation to the AIOU were also considered as the sample of the study.

\subsection{Data Collection}

For gathering the first-hand information, 109 case files from the past 5 years were selected for gathering the information from the registrar office of the AIOU. All the cases were filed in the civil courts. Ordered passed by the lower courts were challenged by the parties to the appellate court. Ethical considerations were fully adhered with and official permission for the review of the legal files was taken from the concerned department in written form. After getting the approval from the concerned department, the case files were reviewed, and critical information was gathered from the selected case files via notes taking. The secrecy and security of the information from the case files was the priority of the researcher due to the sensitive nature of the information. The title of the cases was given pseudonym for report writing. From the data gathered through the review of the information in the case files, the researcher critically identified the core themes and sub themes and made a semi-structured interview questionnaire in relation to the objectives of the study. The researcher gathered the perceptions from the lawyers and management focal persons at AIOU who remained in contact with the case proceedings; raised or followed by the employees of AIOU. This information helped the researcher in better understanding of the situation and exploration of the findings as to how the legal matters are faced by the human resource department of the public sector university.

For getting the answer in relation to the objectives of the questions, the researcher developed the two semi-structured interview modules with seven questions addressing each of the objectives of the study. The responses of the participants were recorded using a digital recorder and then translated and transcribed for the purpose of analysis.

\subsection{Data Analysis}

The current study was aimed to explore the legal issues faced by Public Sector University in managing human resource. The study focused to explore the factors in legal issues that are affecting the human resources practices in higher educational institution along with exploration of the gaps between law and procedures of human resource managing with their implementation. The study also helped in exploration and identification of factors affecting the legal system from relevant cases to involving human resources management issues. According to Saunders et al. (2009), there is no standard method to analyze qualitative data. The term qualitative is referred to the use of non-numerical data which can also refer to information more than mere words and can include pictures or video clips also (Saunders et al., 2016). The goal of qualitative research is to examine a research topic from the perspective of the interviewees or documented data to understand why and how a particular viewpoint is maintained (Cassell and Symon, 2004). 
This analysis includes the analytical findings from the legal case files along with annotations from the participants and analytical interpretations for the achievement of research objectives.

\section{Data Interpretation and Findings}

The qualitative data collected through the review of case files and interviews from the legal personnel and focal person from management was arranged, organized, cleaned and coded for the thematic content analysis which is one of the most reliable and significant qualitative analysis techniques. The data collected from the case files and responses of the legal personal was read repeatedly for the identification of similarities and patterns within the collected data. Open coding process was adopted to identify the themes and sub themes manually from the qualitative data. NVivo 12 software by QSR was used for the computer aided qualitative data analysis (CAQDAS) of responses from the legal personal and focal persons from management.

The data were gathered from the 20 most significant case files. The status of these cases was in different stages of proceeding i.e., case withdrawal, pending for hearing, stay granted, decisions in favor of petitioner or University and in some cases, appeal was pending. For the anonymity reason, the actual case numbers and titles of the cases have been replaced with pseudo case numbers.

The analytical review of the case files revealed that most of the employees were unaware of their legal rights and responsibilities and it seems that most of the cases filed by the employees were because of frustration and lack of legal knowledge. Another fact observed during the analysis is that some employees were totally unaware about the rules and regulations in relation to the promotion and development of individuals. Another important aspect noted during the analysis is that currently the university has hired employees on two bases i.e., a) regular basis, and b) contractual basis. From the cases filed by the petitioners, it can be assumed that most of the contract employees were of the view that after getting job in the university on contract basis, they get entitled to become permanent employees after lapse of fixed amount of time.

A very interesting fact observed in relation to the decision of the employees to go towards legal proceedings in case of a university is that even after getting dismissal of case or decision not in favor of the petitioner, the petitioner rather than accepting the judgment of the lower-level courts (district courts) re-appeal in the higher-level courts. This not only lingers the procedure of provision of justice, but also puts an extra burden on the legal department of the university as they must pursue the case again in the higher courts. A major finding in this regard from the case files was that such cases have been in legal proceedings since few years and still any decision is to be made by the higher courts. This extra burden on the legal and human resource department of the university not only hinders the performance of relevant departments, but also prove to be a problem of constant pursuit for the legal and human resource department due to which the relevant departments and its personnel might fail to perform their duties fully in the capacity they were deemed to perform. 
Table 1

Themes Emerged for the analysis

\begin{tabular}{lll}
\hline S.No. & \multicolumn{1}{c}{ Themes } & \multicolumn{1}{c}{ Sub-themes } \\
\hline 1 & $\begin{array}{l}\text { Awareness about legal rights and } \\
\text { responsibilities }\end{array}$ & $\begin{array}{l}\text { Awareness about legal rights and } \\
\text { responsibilities }\end{array}$ \\
2 & $\begin{array}{l}\text { Perception of employees aboutthe } \\
\text { nature of their job on contract status }\end{array}$ \\
3 & $\begin{array}{l}\text { Re-appeal in higher courts after } \\
\text { unfavorable decision from lower } \\
\text { courts by the petitioner }\end{array}$ \\
\hline
\end{tabular}

From the analysis of the data present in the case files, three basic themes emerged for the analysis of the responses from the people, gathered through the semi-structured interviews. These themes were presented in the table 1 .

Theme 01: Awareness about legal rights and responsibilities

Sub theme 01: Knowledge of university rules and regulation

Theme 02: Perception of employees on nature of their job contract status

Theme 03: Re-appeal in higher courts after unfavorable decision from lower courts by the petitioner

Data from the legal practitioners was gathered in relation to the above mentioned themes and each theme in relation to the responses of the legal personnel has been explained as under.

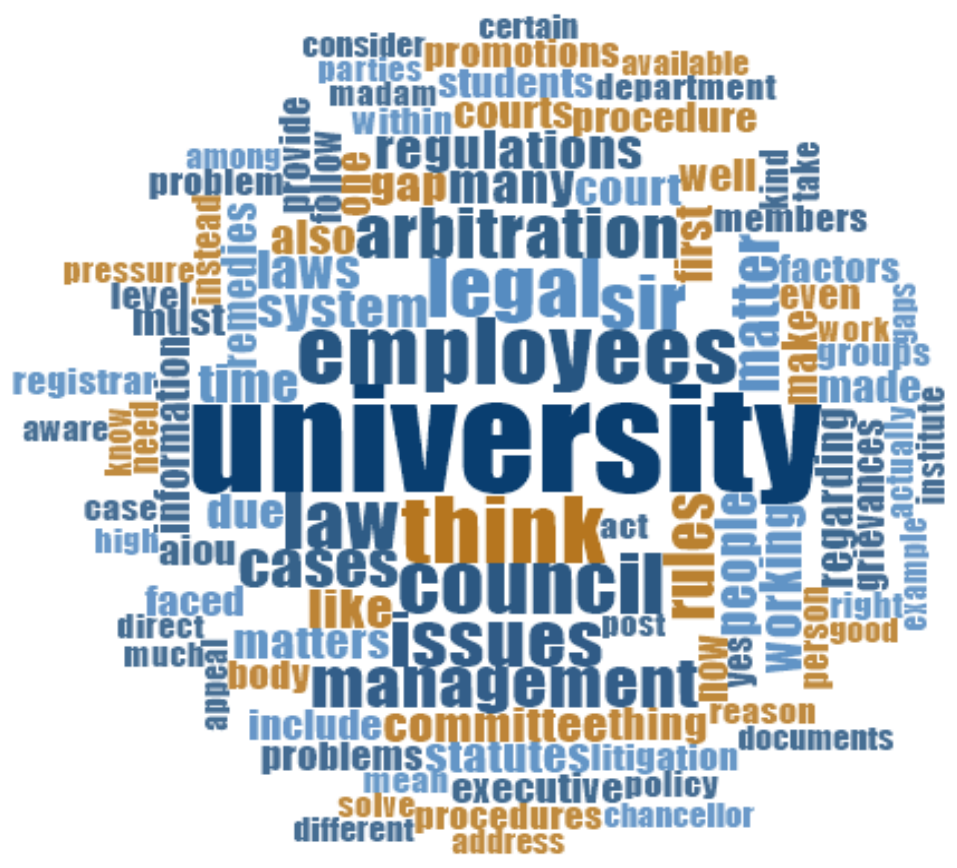

Figure 1: data analysis presentation (Word cloud) 


\subsection{Theme 01: Awareness about legal rights and responsibilities}

Awareness and knowledge about the rules and regulation is a critical part that seems to be neglected by the employees of the university especially the lower-level staff or the staff on contractual basis. This brings problem in future when any matter is brought up by the human resource department which is not in favor of the employee. The matter was discussed by a senior advocate in an interview as following:

"As a matter of fact, employees cannot have the proper set of justice which results into their self-insecurity and uncertainty, the reason for not knowing the justice which is therefore in mind of employee of the university, causes them the mental torture and agony. As the law says, "ignorance of knowledge of law is no excuse".

The additional registrar of the public university mentioned that the university has a clear and concise quota system for the hiring and promotion of the employees. This information should be made available to the individuals during the hiring or enrolment process, but should also be publicly available on the internet. It is the duty of the individuals to go through the relevant information and find what suits them the best and get a better understanding as to what their rights and rules are and what the regulations says. The additional registrar stated,

"The rules say that if the quota is disturbed and too many persons have been appointed already then it goes to direct inductions so when we follow these rules which our university has adopted provided by Govt. then everybody starts to criticize for which I would say that there should be transparency and these posts must be displayed on the web to provide firsthand information to the public and which is also necessary as a documentary evidence against the case filer."

When a senior advocate is asked about their views in relation to the rights and responsibilities of the employees, the senior advocate was of the view that the public university already has a statutory law. But, in practice, the law is not currently prevailing in its full essence which might bring insecurity and dissatisfaction in the minds of the university employees. The senior advocate stated,

"To the extent of the legal remedies for the employees of the university, AIOU 1974 was promulgated and that is a statutory law but the relationship of the employees of the university that of the master and servant. It means that despite their rules and regulations governing the terms and conditions of the employment but still there is no security of jobs to the employees even they are permanent employees of the university."

In relation to the knowledge about rights and responsibilities, a very important aspect is that the individuals of the university should have the complete knowledge about the rules and regulations prevailing in the university. For this, perceptions of the participants are provided in sub theme as under.

\subsubsection{Sub theme 01: Knowledge of university rules and regulation}

When asked about the rules and regulation prevailing and practiced in the public university, the registrar of the university provided a complete picture as to what rules and regulations are currently prevailing and how they are practiced. The registrar stated,

"AIOU is using its acts and statutes for governing its employees' rules and regulations, appointments, promotions and transfers in the light of Government policies. No Government Policy is automatically applicable to AIOU employees. It is only applicable after approval of executive council'. 
The annotation provided by the registrar clearly depicts that the "executive council" of the university is the sole body which makes any rule or regulation being practiced. Without approval from the executive council, no new law, rule or regulation can become part of practicing legislature or gets statutory status. The registrar further explained,

"Under Chapter 5 of the AIOU act 1974 these statutes for the university employees are framed and recommended by the executive council to the pro chancellor and upon his approval it becomes forcible in the university. AIOU also seek guidance from the Government regarding rules for its appointments, transfer, promotions etc. which are available in AIOU Act Statutes"

It is assumed that the general dealing and practicing of statues might fall under the section or umbrella of registrar department in a public university. However, the additional registrar provided the views that the HR and executive council of the university work along with each other. Hiring of employees in a public university is a direct matter of human resource department. However, many other additional components like setting of criteria, advertising the job opportunity, planning phase, and the most important factor of training cannot be done without the approval and association of executive council. Training of the employees is the most critical part as that makes them understand the rules and regulations of the institution and make them adhere to the rules. This also helps in setting the bar as to how new inductions will be made and how the current employees will be promoted in the hierarchy. The additional registrar provided his views in these words,

"As a separate section being headed by registrar or deputy registrar, training was also a necessity separate section because the HR is a holistic approach and all the sections have to be addressed collectively So first thing that we did I think in 2017 when it was approved by executive council and after all the related tasks which comes under the umbrella of HR like planning, recruitment, creation of posts, criteria, advertisement, and induction and lastly the training which adopts a very compulsory role which needs to be passed out. After their training we issue them certificates to process them at next level so, during the training of the badges we have dropped who could not qualify for and they were provided for second chance."

The additional registrar further provided his views that after training, it is considered that all the employees have complete knowledge and understanding about the rules and regulations set up in the university and it is assumed that they will follow the statute to make a comfortable environment. This not only brings personal growth to the employee, but also helps in bringing the factor of competition in the institution. Additional registrar commented on personal growth and competition in these words,

"Yes, I agree that the right to information is true a thing and an individual should be aware of his status during competition. But often we have a perception that as we tell them more about their status, they start creating more issues. Because when a competent take part in competition he is not ready to accept any loss because we have a trend ongoing that we don't accept the success of other and our failure because we think as victim our self. And I think that when boards take decisions they are on merit because some people outshine and its agreeable to select someone who outshine unanimously." 
In relation to the knowledge about the rules and regulation, the senior advocate provided the views that a proper job description along with the full details are provided to the candidates in the written form. The senior advocate provided the views in these words,

"There is employees' hierarchy, which is given to them in written form. When employees are not satisfied with them, then they go to the court of law. People don't have trust on their credibility."

The senior advocate further provided that the filling or defense of petitions without the knowledge and understanding of rules, regulation, and responsibilities, is to bring extra and unwanted burden in relation to the wastage of time, efforts and resources of the university. The senior advocate provided her views in these words,

"So, this embarrassing cycle of litigation is very harmful to the university resources due to lack of legal education. Time management and your cost effectiveness are the basic things which you have to curtail, and it is not possible until you don't educate your HR."

\subsection{Theme 02: Perception of employees on nature of their job contract status}

The public university has two types of employees i.e., fixed term or regular employees and contractual employees. The respondents of the semi-structured interviews provided the view that most of the employees who had contractual or temporary employment are of the view that they would fall in the category of permanent employees after completion of certain period. This is not actually the case as per the rules, regulations, and policies of the public university. One of the seniors from registrar provided his views in this relation in these words,

"This was a major legal issue that we faced regarding litigation brought by temporary employees which include labourers, daily wagers, contract base or who come through family assistance. They think that they should be appointed regularly without competition and for which govt. provide no as such policy and Courts Direct us to follow the rules and 'Their Policy.

He further provided,

According to them we are obliged to provide them opportunities through competition and through this some of the employees were inducted also following that policy cycle some were dropped who went for litigation having no other option. So, most of the litigation we received from the employees are about, promotions and regularization. But fortunately, most of the cases go in AIOU's favour because we are following rules described by Govt.'

The registrar of the public university was of the view that the employees of the public university donot follow the rules and regulations. He provided with the view that, employees have made presumptions without thinking that they are eligible for a particular benefit or not. And they want everything to go in their favour. The registrar explained this scenario in these words.

"I just explained earlier our employees don't follow the rules. They only want that their grievances should be addressed at any time without any limitations."

"Any such committee in the eyes of law has no existence. AIOU has been signing many contracts and agreements to define the arbitration rules. As of my opinion in many cases we always preferred for arbitration at the main campus Islamabad. In many MOU's vice chancellor is the authority and in other cases local administration as per arbitration rules. Arbitration Act is there whether the other parties are working under it or not. For each 
contract we are hiring the services of security agencies. We are going into an agreement with HEC. And thus, each and every activity has different modes. But other parties have different laws. For the arbitration council it is not possible to interfere with those laws. There is a conflict."

\subsection{Theme 03: Re-appeal in higher courts after unfavorable decision from lower courts by the petitioner}

In relation to the laws prevailing in the public university and how the university comes under the law-abiding bodies, the registrar of the public university provided the following views,

"Under Section 3 of chapter 2, the university is cooperative body by the name of AIOU and shall have perpetual succession and commence beingnot a statutory body we do not come under the definition of civil servant and thus we have to seek remedies from the civil courts and other courts."

In relation to the rules and rights of the employees, the registrar provides that there is a proper channel that needs to be followed by the employees in the statutes. The registrar provided his views in these words,

"Section 31 Chapter 7 General Provision of the university act provide the right of appeal and review by the executive council to the employees and against the question of executive council one can appeal to pro chancellor in case of internal adverse orders."

In relation to addressing the legal procedures that needs to be followed, the additional registrar of the public university provided that all the matters should be addressed in the manner as described and practiced. The additional registrar provided his view in these words,

"I think that on a department level an independent committee forum should be an option which should be primary forum to address the problems at first hand. And after that we can consider arbitration before the court proceedings. In other case court should not entertain any matter. For this I would say, suppose if someone is punished on disciplinary proceeding, he has an option of departmental appeal. For servant below 16 grade there is a process of vice chancellor and for those above there is executive council after availing these remedies there are possibilities of high courts. But it is often seen that high court doesn't interfere with self-made statutes by the university and cases are submitted to civil courts then and so the remedies are availed thus."

When the senior advocate was asked to provide his views about the legal procedures and proceedings, the senior advocate was of the view that the legal department of the university is already very efficient and effective. However, the only problem prevailing in this relation is that the procedures and practices are not followed in their true essence. The senior advocate provided,

"I think your law department is very efficient and your deputy registrar is very cooperative to us. They provide each document which we ask for. They himself know quite well about the law that is why he knows everything about the matters under discussion, so we don't have to make much effort to come to the conclusions. Which is very good thing and I have no difficulties understanding and solving your cases." 
When it was asked about existence of any arbitration council on which both parties have trust to resolve the issues and matter in a university before approaching to the court's focal person from registrar department who explained:

"Any such committee in the eyes of law has no existence. AIOU has been signing many contracts and agreements to define the arbitration rules. As of my opinion in many cases we always preferred for arbitration at the main campus Islamabad. In many MOU's vice chancellor is the authority and in other cases local administration as per arbitration rules. Arbitration Act is there whether the other parties are working under it or not. For each contract we are hiring the services of security agencies. We are going into an agreement with HEC. And thus, each activity has different modes. But other parties have different laws. For the arbitration council it is not possible to interfere with those laws. There is a conflict."

Another legal advisor suggeststhat there must be an independent grievances committee for resolving the issues between employee and employer other than the existing system of availing remedies.

"I would say an example of an act which was made in 1973 which address newspapers employees' problems where they raise an institution ITNE. And all litigations of employees who are working in Pakistan newspaper go to them. Same is the concept of grievances committee of which you are talking about. Where you select a representative from each union and select an impartial person who arbitrates between both parties to solve the matter.

I would like to say that if you see at the laws of any developed country like US andUK, they are consisting of many such tribunal and purpose of these tribunal is to compensate the burden of courts there for speedy justice.

While I was on a research in the US, I discovered that each university is composed of a grievances unit to address such matters like student's redressal grievances committee and employee's redressal grievances committee, and they have the representation from each side

So, we should take inspiration to rule out our problems even if needs any changes in the law because it hardly matters when we are saving our energy and investment, I would say this is the demand of present circumstances to adopt this attitude. Until you don't try something new you would not be able to know that whether it's effective or not, so this was my concern about the recent strategy".

The model shown in the figure 2 was developed from the information received from the interviewees of the study in reply of the current procedural legal remedies for the parties. 


\section{Existing Model for Legal remedies}

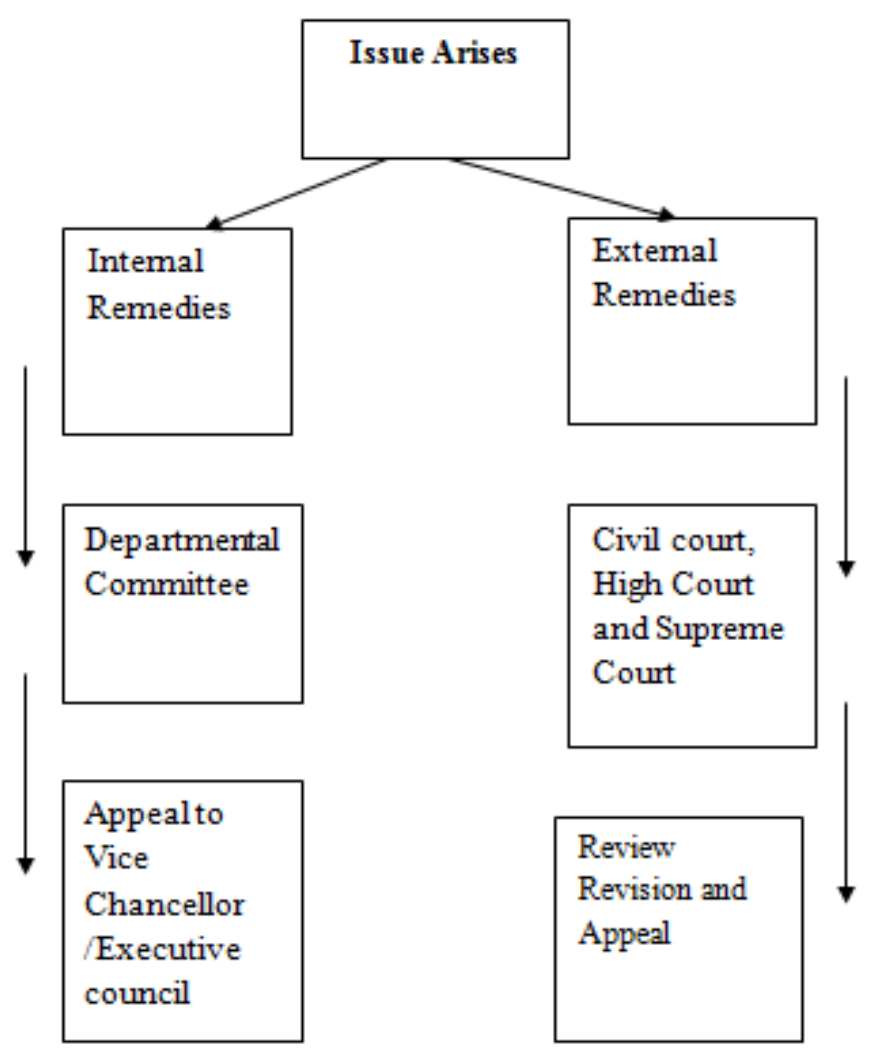

Figure 2 Existing Model for Legal remedies

\section{Conclusion}

In relation to the analytical findings of the study from the analysis of the case files and the data from the semi-structured interviews, it can be summed up that there are major gaps between the actual laws applicable for the governance in the public university and the actual practices in which those laws are being implemented. There are some gaps, but they should be in line with the statutes and basic prime constitution. And the slight variation among them which are contradictory to constitution should be eliminated. The response of the participants showed that some regulation and statues were amended where they were weak in its spirit, but they are still needed to be observed. For further refinement more work is needed to get familiarity with them during their implementation. Although, a lot has been improved in the past and many people have got relief due to efforts of the people.

Employees of the public universities should be provided and promoted to gather complete knowledge about the rules and regulations prevailing in the university so that no mishaps can happen, and employees should not opt without reason to go towards the court,short of following the arbitration procedure first as that would just bring waste of time, money, and efforts. The contractual or temporary employees should have clear view as to why and how their job description 
especially the promotion procedure works, so they donot make any assumptions in their mind which later bring problem between the individual and the institution.

\section{Recommendations}

\section{Proposed Model for Legal Remedies}

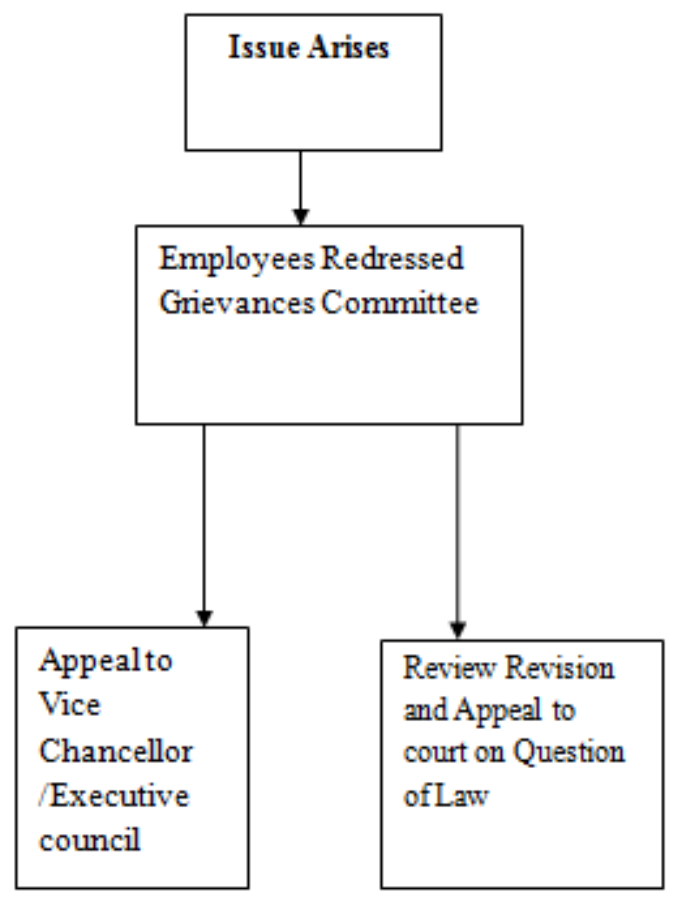

Figure 3 Proposed Model for Legal Remedies

On the bases of the findings and conclusion it is recommended that to lessen the burden of litigation on courts and consequences of litigation, university may have an independent employee redressed grievances committee as the first remedy to resolve the issues at university level. Courts, Vice Chancellor/ Executive council (Syndicate) will be the review, and appellate authority according to their jurisdiction of hearing of cases. The proposed model of the legal remedies is given in figure 3 .

\section{References}

Abdulai, A. (2000). Human resource management in Ghana: prescriptions and issues raised by the Fourth Republican Constitution. International Journal of Public Sector Management, 13(5), 447-466. http://dx.doi.org/10.1108/09513550010350841

Ahmed, S. (2010). Human Resource Management in Public sector Universities \& Changing Trends. Presentation, Khyber Medical University. 
Arif, M., \& Hasan, A. (2013). HRM Practices in Public and Private Universities of Pakistan. In 3rd International Conference on Business Management. Lahore. Retrieved from https://cgr.umt.edu.pk/icobm2013/papers/Papers/IC3-Dec-2012-069.pdf

Ashraf, J. (2017). Examining the public sector recruitment and selection, in relation to job analysis in Pakistan. Cogent Social Sciences, 3(1). http://dx.doi.org/10.1080/23311886.2017.1309134

Cassell, C. \& Symon, G. (2004). Essential guide to qualitative methods in organizational research, Sage.

Clardy, A. (2003). The Legal Framework of Human Resource Development: Overview, Mandates, Strictures, and Financial Implications. Human Resource Development Review, 2(1), 26-53. http://dx.doi.org/10.1177/1534484303251236

Dubravska, M., \& Solankova, E. (2015). Recent Trends in Human Resources Management in Selected Industry in Slovakia and the Czech Republic. Procedia Economics and Finance, 26, 1014-1019. http://dx.doi.org/10.1016/s2212-5671(15)00924-7

Flowers, P. (2009). Research philosophies-importance and relevance. MSc by Research. Cranfield School of Management.

Ijaz Khan, Q., \& Shamsudin, A. (2016). The Mediating Effect of Career Success on HRM Practices and University Performance: A Study from Public Sector Universities of Pakistan. International Journal of Economics \& Management Sciences, 5(4). http://dx.doi.org/10.4172/2162-6359.1000351

Iqbal, M., Arif, M., \& Abbas, F. (2011). HRM Practices in Public and Private Universities of Pakistan: A Comparative Study. International Education Studies, 4(4). http://dx.doi.org/10.5539/ies.v4n4p215

Murphy, K. (2018). The Legal Context of the Management of Human Resources. Annual Review of Organizational Psychology and Organizational Behavior,5(1), 157-182. http://dx.doi.org/10.1146/annurev-orgpsych-032117-104435

Pathirage, C. P., Amaratunga, D., \& Haigh, R. (2005). Knowledge management research within the built environment: Research methodological perspectives.

Rosenbloom, D. (2010). Public Sector Human Resource Management in 2020. Public Administration Review, 70, s175-s176. http://dx.doi.org/10.1111/j.15406210.2010.02267.x

Saunders, M. L., \& Lewis, M. P. and Thornhill, A. (2009) Research Methods for Business Studies. Saunders, M., \& Lewis, P. (2016). In Thornhill Adrian. Research methods for business students, 7 